Journal of Advanced Research in Business and Management Studies

\title{
Temptation and Unethical Activities: A Study on Malaysian Students' Behaviour
}

\author{
Mohamad Naimi Mohamad Nor ${ }^{1,}$, Noor Afza Amran ${ }^{1}$ \\ 1 ASIAN Research Institute for Corporate Governance, Universiti Utara Malaysia, 06010 UUM Sintok, Kedah, Malaysia
}

\begin{abstract}
This study compares the differences among students on the influence of temptation and the acts of misconduct that they might commit. Several students' characteristics were employed to examine the differences in terms of the possibility of the students to commit unethical activities. A three-section questionnaire was distributed to students from October 2019 to November 2019. A total of 319 accounting students from Universiti Utara Malaysia (UUM) were involved in this study. For data analysis, descriptive and comparative analyses were utilised. The comparative analysis looked into the differences in terms of demographic (gender and ethnicity) and academic (year of study and academic programme) factors. The descriptive analysis reveals that there is a possibility of students being involved in an unethical behaviour when they are tempted and the intention to be involved in that behaviour is generally low. Based on the comparative analysis, this study reveals that the most significant difference arises for the demographic factor, i.e., gender. The comparative analysis for academic programmes reveals there are not many significant differences among students in the case of becoming involved in an unethical activity when tempted and intention to commit unethical behaviour. The results may give some insights to relevant authorities, such as the Ministry of Education, regulators, business owners and the public at large, on current students' intentions and behaviour. It might be useful to the relevant authorities to start thinking of and developing appropriate fraud prevention mechanisms.
\end{abstract}

\section{Keywords:}

Temptation, Unethical activity,

\section{Introduction}

Various business scandals which have occurred around the world, have attracted the attention of the public, regulators and shareholders, to scrutinise top management's behaviour. These scandals are not confined to developed countries per se; in fact, business failure has become a crucial issue in developing countries as well, such as Thailand (Krung Thai Bank); the Philippines (Metropolitan Bank $\&$ Trust Co.) and Malaysia (1MDB). These scandals have drawn the attention of various parties, including business analysts, due to the fact that they involve a large amount of money and have been committed by a person or persons, entrusted and given the mandate by shareholders to manage the company (board of directors and managers). A worst case scenario is when the scandals also involve

\footnotetext{
* Corresponding author.

E-mail address: naimi@uum.edu.my 
or are orchestrated by accountants or financial controllers, who are supposedly responsible for preparing reliable corporate reports and maintain good governance practices.

Incidences, such as manipulating the financial statement, have lead regulators to introduce new business rules and revise existing ones, specifically in terms of penalities, so that such incidences can be prevented, and make perpetrators more aware of the consequences. These new and revised rules perhaps can enable shareholders to be more vigilant and prevent corporate collapses. In fact, it has been argued that business failures and collapses are partly due to unethical behaviour (e.g., improper asset valuation, lack of accounting disclosure, etc.) of top management $[1,2]$.

As such, a number of measures are being taken by regulators to preclude such incidences, for example, improvement of the business legal framework. In Malaysia, the Companies Act 1965 was amended in 2016 and the Malaysian Code on Corporate Governance 2012 was revised and became effective in 2017. This is highly commendable since business scandals are becoming more complicated and perpetrators more sophisticated. Further, the prevalence of business scandals might affect foreign investors' confidence on the quality of corporate governance, including management's ethical values.

As business collapses are being associated mostly with unethical behaviour of the management, one of the ways to preclude such incidences is by improving prevention mechanisms. To ensure the effectiveness of prevention mechanisms, studies on the effects of unethical behaviour must be conducted to create awareness among the current or future business leaders. Questions such as, 'What are the factors that drive people to commit unethical behaviour?' and 'What are the types of unethical behaviour that people commit?' must be answered. By answering these questions, some effective intervention plans can be formulated, and perhaps, the number of corporate failures in the future can be minimised.

Prior studies have revealed several reasons as to why a person may be involved in unethical behaviour. In the area of fraud investigation, three key factors have been identified as the main contributors to this behaviour as follows: (i) opportunity; (ii) pressure; and (iii) rationalisation [3].

Tang and Sutarso [2] found that temptation can lead to unethical behaviour; in other words, unethical behaviour may occur when a person has a high degree of tendency, desire or drive, to do so. Based on the premise that tempation leads to unethical conduct, it is believed that the occurrence of unethical behaviour in business practices, is also attributed to the temptation factor. Therefore, this study investigates the possibility of future business leaders (i.e., students) being influenced by temptation and their intention to be involved in unethical behaviour. Specifically, this study examines the differences among individuals with regards to: (i) temptation to commit unethical behaviour; and (ii) intention to commit unethical behaviour. Two main characteristics are used, namely: demographic attributes ${ }^{1}$ and academic background. The findings of studies related to ethical behaviour can also help identify the characteristics and factors that contribute to the increasing number of cases of unethical behaviour.

The process of fraud or unethical activity detection is complex. Therefore, a study of one's intention to engage in unethical behaviour can give some indication as to why unethical activities are carried out. Further, a study involving students can provide insights into the future patterns or trends of possible criminal events. These students are future leaders and will also be key drivers of a country's economic development. Therefore, it is important to understand the thinking of today's students as they are the ones who will determine the quality of organisational and governance practices of business organisations, which they will become a part of in the future. Further, in the increasingly evolving business world, where many challenges exist, such as lack of auditor

\footnotetext{
${ }^{1}$ Demographic or personal attributes will be used interchangeably throughout the article.
} 
independence, decaying moral and ethical values and the myriad key performance indicators that need to be achieved, understanding how they will respond when there are so many temptations, is vital.

In practice, the detection of fraud activity is challenging since it involves several processes and procedures (such as identifying the red flags, categorising the fraud) that must be carefully executed. Hence, it is appropriate to employ "intention" as a measure to anticipate the possibility of an unethical behaviour to occur [4]. This is also in line with the argument by Lawson [5] and Sims [6] that cheating in the classroom might lead to or be an indication of cheating in the work environment since the values and beliefs that students possess today will shape the way they think and behave in future.

This study is an extension of an earlier study by Owusu et al. [4] in African countries. However, the current study is executed in one of the Asian countries (i.e., Malaysia), which has a different business environment and culture compared to Africa. Further, this study incorporates the element of ethnicity, that is believed to influence one's intentions and behaviour. The study then compares the differences among respondents in order to understand the role of temptation in unethical behaviour intention.

The next section reviews prior literature and followed by the methodology section. The next sections are on the findings, results and discussion, and finally, a conclusion of the study.

\section{Review of Literature}

\subsection{Malaysian Business Environment}

Malaysia is an Asian nation of diverse ethnicities, with three major ethnic groups, namely Bumiputra ${ }^{2}$, Chinese and Indian. Based on the current population estimates, Malaysia, 2019, issued by the Department of Statistics Malaysia, the percentage of Bumiputra is $69.3 \%$, followed by Chinese (22.8\%), Indians (6.9\%) and Others (1\%). In terms of business, most are controlled by the Chinese ethnic group compared to other groups. In addition, many small and medium-sized companies are also Chinese-owned, while large-sized companies are government-owned (through federal, state or government investment agencies) and family-owned companies (mostly held by Chinese families). The dominance of the Chinese ethnic group in the private sector indicates their economic strength, and normally, the business empire is passed on to family members. This is a common practice and it does not apply only in Malaysia, but also in Hong Kong, Indonesia and Singapore. This implies that the Chinese are competitive, prioritise family relationships, make strategic decisions and take risks $[7,8]$.

Although the Malays are the majority, their presence in business and commerce activities is relatively low; Malays normally require various kinds of assistance given by the government. Therefore, the contributions and assistance (knowledge, capital, legal) offered by the government to the Malay ethnic group are still considered important by the Malays for empowering their business. As for Indians who are characterised as being loyal, God fearing and hardworking [8], their involvement in the economic sector is relatively low. The equity ownership held by the Indian Malaysian community is less than 3\% (https://www.thestar.com.my/business/businessnews/2019/05/20/new-investment-vehicle-to-uplift-indians/).

\footnotetext{
${ }^{2}$ Bumiputra or sons of the soil mainly belong to the Malay ethnic group (about $60 \%$ ).
} 


\subsection{Unethical Behaviour and Consequences}

Unethical behaviour is an act performed outside the scope of morality which is unacceptable or inappropriate. According to Gino [9], an unethical behaviour or immoral activity consists of the following characteristics: (i) it has negative effects or is harmful to others; and (ii) it is a breach of the rules and regulations and the action is morally not acceptable by many people, as a whole. Ethical behaviour, on the other hand, is the practice or action which is in line with moral standards determined by the society.

One of the common types of unethical behaviour in the corporate sector is the commitment of fraud. Fraud is a form of unethical behaviour or offense that contravenes rules and regulations, and allows the perpetrator to acquire personal or financial gain. Fraud is also an activity that is committed to deceive others, often by making false justifications or claims. Examples of fraud are corruption and forgery of business documents. Fraud is a serious corporate problem for every company and the rate of fraud incidence is increasing over time. This unethical activity has a wide range of adverse effects on individuals, organisations and countries. Fraudulent acts have caused significant losses to companies, including the costs of investigation, legal, prosecution, human resources, internal control, monitoring and discipline. The greater costs involved is reputational damage and this damage can negatively affect the confidence of the shareholders toward the business organisation.

In Malaysia, several fraudulent incidents have occurred involving companies listed on the stock exchange. Such incidences can affect the quality of the stock market and the credibility of the financial statements of the company. For example, corporate scandals involving Silver Bird Group Bhd. finally forced the company to close down (source: https://www.theedgemarkets.com/article/high-5-we-had-no-choice-close-down). In this case, what is alarming is that both the internal and external auditors of the company were summoned (i.e., monetary effect). This, in turn, affected the credibility of the auditors and directors of the company who were supposedly to play a role in safeguarding shareholders' interests.

\subsection{Intention}

Intention is a person's determination or the motive to act. This intention arises from one's intuition. According to Fishbein and Ajzen [10], intention is the possibility for an individual to be involved in certain behaviour. It relates to the seriousness and to the inner self of the individual. According to Ajzen [11], the stronger a person has the intention to perform an action, the higher the likelihood that the person will be involved in the action. Specifically, in the context of this study, it can be said that the stronger the intention to do something unethical, the stronger the likelihood of the person to act unethically.

Several studies have employed intention as the subject of study. For instance, Ismail and Mohamed [12] examined the ethical intention among students; they examined the association between ethical ideologies, Machiavellianism (using the amoral approach for personal benefits) and gender and ethical intention. Among other findings, they found that Machiavellianism is negatively associated with ethical intention and gender does not influence the ethical intention. In other related studies, based on moral theories, Jamil, Mohammed, and Ramu [13] examined the antecedents of unethical behaviour among students in business schools. Their study shows that moral philosophies (egoism and utilitarianism) and subjective norm positively influence unethical behaviour intention.

Ruiz-Palomino, Bañón-Gomis, and Linuesa-Langreo [14] took another approach by examining the influence of peers' unethical behaviour on bank employees' ethical intention. The study claims that through Machiavellianism, unethical behaviour of peers indirectly influences employees' ethical 
intention. Interestingly, the combination of high Machiavellianism and ethical peers, can reduce the negative effect of Machiavellianism on staff members' ethical intention. Meanwhile, based on the theory of planned behaviour, Nga and Lum [15], who examined unethical behaviour among private university undergraduate students, showed that egoism and utilitarianism and their level of consequences, strongly influence unethical behaviour. Ruiz-Palomino et al. [14], however, indicated that the role of peer influence is insignificant.

Based on the discussion above, the trend of commercial crime or fraud in the future can be determined by students' attitudes and thoughts today. Hence, the incidence of academic dishonesty among students must be resolved as quickly and thoroughly as possible. The involvement of students in an unethical activity led to the emergence of issues relating to the university's effectiveness to develop civilized society [13]. As ethical values could shape the character of future corporate leader [15], therefore, the effort to instill business ethical values to university students must be encouraged and supported.

\subsection{Temptation and Intention to Commit Unethical Activities}

Temptation exists within every individual. Generally, temptation is associated with the desire to do something wrong. Tang and Sutarso [2] and Chen, Tang, and Tang [16] explained that people may fall into temptation because of the following reasons:

(1) Attitude:

(i) getting rich; (ii) impulsive behaviour; and (iii) cognitive impairment;

(2) Social norm:

(iv) social moral values; and

(3) Perceived behavioural control:

(v) lack of self-control.

Based on the above reasons, the temptation arises due to the need for physical things (e.g., wealth); and the inability of the person to control himself/herself, thoughtless conduct and decaying moral values. Temptation will give individuals strength and drive them to do something that is morally unacceptable. An action or activity may not happen if there is no element of temptation to act. This is consistent with Hsiao and Yang [17], who investigated the factors of cheating intention among part-time students. Based on the theory of planned behaviour, their study shows that perceived behavioural control, professional unethical belief, subjective norm and attitude, influence cheating intention. In a related study by Owusu et al. [4], they show that there is positive relationship between some elements of temptation and the possibility of engaging in unethical activities. These elements are cognitive impairment, getting rich and lack of self-control. Using the same theory of planned behavior as employed by Hsiao and Yang [17], the subsequent analysis by Owusu et al. [4] showed that attitude and perceived behavior were also positively related to the tendency to commit unethical activities.

According to Gino, Schweitzer, Mead, and Ariely [18], doing something unethical is a person's choice because it offers short-term benefits. Indeed, involvement in unethical actions can have an impact on the perpetrator, the environment and the whole community. It is crucial for the perpetrator to think deeply and wisely in order to exercise self-control from being influenced by negative intentions. As such, temptation should be carefully controlled by individuals as it affects intentions that ultimately lead to an unethical activity. 


\subsection{Demographic and academic factors of unethical behaviour}

Based on the causes of temptation as outlined above, the existence or the level of temptation can be associated with several factors. Among the contributors to temptation are demographical and academic factors of the individual $[19,2]$.

Demographics is a study of the population and describes the structure, size and composition of the population of a certain region or country. Demographics consists of the background of a person, such as gender, ethnicity and religion, and all these elements would reflect the character of the individual.

For the purpose of this study, the demographic factor is represented by gender and ethnicity. In terms of gender, it is said that women are more concerned with their image, are risk averse and less overconfident, have higher possibility to comply with business regulations, are caring and helpful and concerned with relationships $[20,21]$. As for ethnicity, according to the Constitution of Malaysia, a Malay is a person who professes the religion of Islam. The religious factor has a strong influence in their daily life and Islam forbids Muslims from committing fraud or engaging in unethical activities. As mentioned earlier, since the Chinese dominate business activities in Malaysia, their business decisions mainly consider how such decisions would impact their family connections [7]. Previous studies on ethnicity, have suggested that the Chinese tend to be individualistic, self-centered and secretive, while Malays are more transparent [22].

Apart from demographic factors, other factors that influence behaviour is the academic or education factor. Education is a means or process of gaining knowledge, skills, values and beliefs, and it is also an agent of change in an individual's way of thinking. The level of education determines a student's skills and expertise [23]. For example, prospective accountants (those with a degree in accounting) will be exposed not only to technical aspects but also to humanities and ethical values. This will allow them not only to be analytical and sceptical, but also possess humanistic values. Two variables under the education factor, were utilised in the current study, namely the year of study and the type of accounting programme. A longer period of study and more learning processes involved can enhance knowledge and shape students' way of thinking. As for the academic programme, two accounting degree programmes offered by the Universiti Utara Malaysia were compared: Bachelor of Accounting and Bachelor of Accounting (Information Systems). ${ }^{3}$ A major difference between these two progammes is the students of Bachelor of Accounting (Information Systems) focus on information systems subjects, to give them hands-on experience to master IT skills. According to Lounsbury, Sundstrom, Levy, and Gibson [24] among major traits of IT professionals which significantly differ from other professionals, are emotional stability (i.e., ability to handle stress, calmness and resilience), assertiveness (i.e., confidence, firm hold on principles) and work drive (i.e., being motivated and productive).

The personal attributes and academic factors discussed above may make a difference in the nature of one's temptation. These factors can also determine the type of unethical behaviour intention involved.

\footnotetext{
${ }^{3}$ As for Bachelor of Accounting (Information System), students are required to take additional courses related to Information Systems (such as Strategic Planning for Accounting Information Systems, Governance of Enterprise Information Technology) area. As for Bachelor of Accounting, apart from the programme's core subjects, students are required to take another five subjects as electives, such as Forensic Accounting and International Accounting.
} 


\section{Methodology}

The sample used in this study are accounting students in Universiti Utara Malaysia (UUM), a public university. Tunku Puteri Intan Safinaz School of Accountancy (TISSA) in UUM is one of the oldest and largest accounting faculties in Malaysia (source: http://tissa.uum.edu.my/aboutus/about-soa) and produces a large number of accounting graduates. Non-first year accounting students were chosen as they have been exposed to business related subjects and can appreciate the effect of unethical behaviour on an organisation.

The study adopted a questionnaire from Owusu et al. [4], comprising three sections, i.e., personal details, temptation and unethical behaviour intention. The first section consists of information about the student's gender, age, academic course, year of study and ethnicity.

The second section of the questionnaire asked the students to indicate their temptation and its possible effect on them. The 14 items of temptation were divided into five categories, namely: (i) getting rich; (ii) impulsive behaviour; (iii) cognitive impairment; (iv) social moral values; and (v) lack of self-control.

As for the last section of the questionnaire, students were required to answer questions on their intention to be involved in unethical behaviour activity. Both the temptation and unethical behaviour items were measured using a Likert scale, from 1 to 5 , where 1 means "strongly agree" and 5 indicates "strongly disagree". Further, this five-point scale was employed to facilitate the students to respond to the statements given, while making it easier for the authors to interpret the respondents' responses.

A total of 562 questionnaires were distributed to the accounting students during the first semester 2019/2020 (i.e., from October 2019 to November 2019). After the screening process, 319 (56.7\%) of the questionnaires were found to be usable and could be analysed. Questionnaires with incomplete information or data were discarded. The data were analyzed descriptively and used the Mann-Whitney $U$ test to look at the differences between students.

\section{Results and Discussion}

\subsection{Descriptive analysis}

The descriptive statistics of the sample is presented in Table 1 comprising 319 samples. Table 1 shows that out of 319 samples, $20 \%$ are male while $80 \%$ are female. The scenario is a norm for management programmes, including accounting, compared to technical courses, for example engineering, which is dominated by males. Most of the respondents are 22 years old, with the youngest being 20 years (0.6\%) and the oldest, 26 (0.3\%). One-fifth of the respondents (64 students) are in the Bachelor of Accounting (Information Systems) programme and others (255 students) are in the Bachelor of Accounting programme. More than half of the respondents are final year or 4th year students (56.4\%), while the rest are in the second or third year of their study. For the ethnicity, nearly $60 \%$ are Malay (190 students), followed by Chinese (85), Indian (35) and Other ethnic groups with nine. 
Table 1

Descriptive statistics of repondents $(n=319)$

\begin{tabular}{c|l|r|r}
\hline Measure & Items & Frequency & $\mathbf{( \% )}$ \\
\hline Gender & Male & 65 & 20.4 \\
& Female & 254 & 79.6 \\
\hline Ethnicity & Malay & 190 & 59.6 \\
& Chinese & 85 & 26.6 \\
& Indian & 35 & 11 \\
& Others & 9 & 2.8 \\
\hline Age & 20 & 2 & 0.6 \\
& 21 & 28 & 8.8 \\
& 22 & 156 & 48.9 \\
& 23 & 49 & 15.4 \\
& 24 & 76 & 23.8 \\
& 25 & 7 & 2.2 \\
& 26 & 1 & 0.3 \\
\hline Academic & Bachelor of Accounting & 255 & 79.9 \\
programme & Bachelor of Accounting (Information System) & 64 & 20.1 \\
\hline Year of study & 2 & 17 & 5.3 \\
& 3 & 122 & 38.2 \\
& 4 & 180 & 56.4 \\
\hline
\end{tabular}

Table 2 shows descriptive analysis for the temptation and unethical behaviour constructs/indicators for the sample.

Table 2

Descriptive statistics on constructs/indicators of temptation and unethical behaviour intention

\begin{tabular}{|c|c|c|}
\hline Constructs/indicators & Mean & SD \\
\hline Temptation & 3.193 & \\
\hline \multicolumn{3}{|l|}{ Cognitive impairment } \\
\hline Temptations provoke me to think and act irrationally & 3.297 & 1.056 \\
\hline Temptations motivate me to behave spontaneously and impulsively & 2.943 & 0.998 \\
\hline $\begin{array}{l}\text { Temptations persuade me to follow my feelings and hearts at the moment and take } \\
\text { action right away }\end{array}$ & 2.824 & 1.073 \\
\hline \multicolumn{3}{|l|}{ Impulsive behaviour } \\
\hline Temptations corrupt me and cause me to make inappropriate decisions & 3.457 & 1.017 \\
\hline $\begin{array}{l}\text { Temptations control my thoughts and behaviours and prevent me from concentrating } \\
\text { on anything else }\end{array}$ & 3.159 & 1.035 \\
\hline Temptations make me feel weak physically, psychologically and spiritually. & 3.426 & 1.006 \\
\hline \multicolumn{3}{|l|}{ Getting rich } \\
\hline Temptations are more prominent to those who want to get rich & 2.877 & 1.043 \\
\hline $\begin{array}{l}\text { Temptations are more salient (important) to those who have a high love-of-money } \\
\text { orientation }\end{array}$ & 2.808 & 1.051 \\
\hline $\begin{array}{l}\text { Temptations provoke me to become selfish and ignore others' needs, rights and } \\
\text { concerns. }\end{array}$ & 3.752 & 0.937 \\
\hline \multicolumn{3}{|l|}{ Lack of self control } \\
\hline Temptations prevent me from thinking clearly about my goals, ideals and plans & 3.498 & 0.980 \\
\hline Temptations weaken the control of my emotions, desires, urges or itch & 3.326 & 1.037 \\
\hline Temptations cause me to lose track of my own behaviours. & 3.463 & 1.039 \\
\hline \multicolumn{3}{|l|}{ Social moral values } \\
\hline Temptations persuade people with status and power to "cave in" to them & 2.937 & 0.972 \\
\hline Temptations are easier to accept when my friends and peers are doing them. & 2.931 & 1.067 \\
\hline Unethical behaviour intention & 4.014 & \\
\hline
\end{tabular}




\begin{tabular}{l|l|l}
\hline Borrow RM20 from a cash register overnight without asking. & 4.100 & 1.219 \\
\hline Take merchandise and/or cash home. & 4.072 & 1.193 \\
\hline Give merchandise away to personal friends (no charge to the customers). & 3.996 & 1.153 \\
\hline Abuse the company expense accounts and falsify accounting records. & 4.116 & 1.308 \\
\hline Receive gifts, money and loans (bribery) from others due to one's position and power. & 4.084 & 1.257 \\
\hline Lay off 500 employees to save the company money and increase one's personal bonus. & 4.003 & 1.201 \\
\hline Overcharge customers to increase sales and to earn higher bonus. & 3.996 & 1.237 \\
\hline Give customers "discounts" first and then secretively charge them more money later r & 3.959 & 1.236 \\
(bait and switch). & & \\
\hline Make more money by deliberately not letting clients know about their benefits & 3.937 & 1.174 \\
\hline Use office supplies (paper and pen), machine and stamps for personal purposes. & 3.774 & 1.092 \\
\hline Make personal long-distance (mobile phone) calls at work. & 3.934 & 1.066 \\
\hline Waste company time surfing on the internet, playing computer games and socializing. & 3.918 & 1.087 \\
\hline Take no action against shoplifting by customers. & 4.047 & 1.127 \\
\hline Take no action against employees who steal cash/merchandise. & 4.166 & 1.195 \\
\hline Take no action against the fraudulent charges made by one's company. & 4.103 & 1.222 \\
\hline
\end{tabular}

Table 2 reveals the mean and standard deviation (SD) scores of the assessment of temptation and unethical behaviour intention. As for temptation, in general, the reported mean is 3.193, thus, this study acknowledges the presence of temptation among respondents.

By looking at individual indicators of temptation, the indicator, "Temptations provoke me to become selfish and ignore others' needs, rights and concerns", has the highest score (mean $=3.752$, $\mathrm{SD}=0.937$ ); and the indicator, "Temptations are more salient (important) to those who have a high love-of-money orientation", has the lowest mean $(2.808, S D=1.051)$. Looking at the category of temptation, the lack of self-control item has the highest score.

In the case of unethical behaviour intention, the reported score is 4.014 , suggesting that intention to be involved in unethical behaviour is generally low. The highest score is for, "Take no action against employees who steal cash/merchandise" (mean $=4.166, \mathrm{SD}=1.195$ ); whereas the lowest score is for, "Use office supplies (paper and pen), machine and stamps for personal purposes" (mean 3.774, SD = 1.092). Hence, for unethical behaviour intention, the students have the tendency to take further action against fraudsters and the students may be more likely to be involved in utilising the company's assets for their own use.

\subsection{Comparative Analysis}

\subsubsection{Demographic characteristics}

In order to understand the different characteristics among students with regards to the constructs of temptation and unethical behaviour, several analyses were carried out. The results are presented in Table 3.

Table 3 Panel A reveals the differences in terms of the gender of the respondents. With regards to temptation, most of the mean values are lower for females except for (i) Temptations provoke me to think and act irrationally; (ii) Temptations corrupt me and cause me to make inappropriate decisions; (iii) Temptations make me feel weak physically, psychologically and spiritually; and (iv) Temptations provoke me to become selfish and ignore others' needs, rights and concerns. Only one indicator has the same mean for both male and female students, i.e., "Temptations cause me to lose track of my own behaviours." The results in this Table reveal that there are significant differences for the items between male and female students for: (i) Temptations provoke me to think and act irrationally; (ii) Temptations are more prominent to those who want to get rich; (iii) Temptations persuade people with status and power to "cave in" to them; and (iv) Temptations are easier to 
accept when my friends and peers are doing them. As for unethical behaviour intentions, the mean is higher for female students compared to their male counterparts. Further, it shows that most of the intentions show significant differences between male and female students, except for, "Take merchandise and/or cash home".

Table 3 Panel B shows the differences for the ethnicity construct of the students. As noted, the Malay ethnic group comprises the majority of the sample (almost $60 \%$ ) versus other ethnicities (Chinese, Indian and others). The result indicates that there are very significant differences for many of the items such as, "Temptations provoke me to think and act irrationally", "Temptations corrupt me and cause me to make inappropriate decisions" and "Temptations persuade people with status and power to "cave in" to them". Two variables, however, are not significant. For unethical behaviour, none of the items shows a significant difference between the ethnic groups.

\subsubsection{Academic characteristics}

The analysis of academic characteristics is demonstrated in Table 4. Based on Table 4 Panel A, for academic programme of the respondents, the only significant item (significant at $10 \%$ level) is, "Temptations provoke me to become selfish and ignore others' needs, rights and concerns", where the reported mean for Bachelor of Accounting is 3.80 and Bachelor of Accounting (Information Systems) is 3.55. Similarly, only one variable is significant for unethical behaviour intention (significant at $10 \%$ level), i.e., "Receive gifts, money and loans (bribery) from others due to one's position and power", where the mean for Bachelor of Accounting is 4.11 and Bachelor of Accounting (Information Systems) is 4.00 .

Table 4 Panel B shows the differences for the year of study of the respondents. The result shows that three items have significant differences, namely: (i) Temptations provoke me to think and act irrationally; (ii) Temptations persuade me to follow my feelings and heart at the moment and take action right away; and (iii) Temptations persuade people with status and power to "cave in" to them. As for unethical behaviour, only "Use office supplies (paper and pen), machine and stamps for personal purposes", shows a significant difference. Other items of unethical behaviour intention do not indicate any significant differences.

\subsection{Discussion}

Based on the results of the study, it is found that the demographic factor is dominant in explaining the differences in people's unethical activities. In terms of the demographic factor, significant differences exist for gender. Four of the items under the temptation construct show significant differences for gender, while almost all the items under the intention to commit unethical behaviour construct, show significant differences. The differences between males and females (gender) are something to be expected as how they think and handle crises and decision-making is different. In fact, Gottschalk [25] argued that white collar crimes cases committed by female perpetrators are much lower compared to male criminals.

In terms of ethnicity, twelve variables are significant in relation to temptation, whereas for unethical behaviour intention, none of the variables are significant. The significant differences arise especially for temptation probably due to the close association between ethnicity and religion as explained earlier. It can be related to some of values allegedly being held by the Malay ethnic group, which among others, emphasise on the relationship between humans and God, self-respect and politeness [8]. It is important to emphasise that culture can shape a person's personality and how 
he or she perceives and handles a certain situation. Hence, the overall results indicate that personal attribute will affect a person's intention to be involved in unethical activity.

With regards to academic background, it is found that for the year of study (final year students vs others), three significant variables are related to temptation and only one is related to unethical behaviour intention. For the type of study programme (Bachelor of Accounting vs Bachelor of Accounting (Information Systems)), only one variable has significant differences for each of the temptation and type of unethical behaviour intention items. Hence, the respondents mainly have a similar view of temptation and unethical behaviour intention regardless of their academic concentration area. In general, the results show that there are not many significant differences for respondents' the academic background factor. This can be due to all respondents taking the same core courses and only a few different elective subjects. In addition, majority of the respondents are at the end of their study period. They have already been exposed to a variety of subjects that are not only related to theory but how they can be applied in accounting practice. Therefore, they have been equipped with sufficient understanding of the aspects of ethics and appreciate the importance of this value in their life. It is also in line with the finding by Nga and Lum [15], that there is no significant difference in the influence of a business major programme on unethical behaviour intention among undergraduate students from private higher education institutions. Thus, it can be said that a person with an almost similar academic background, has a similar mindset with regards to fraud; and education has an impact on the way a person thinks and subsequently determines his or her course of action.

Overall, the most significant differences are for demographic characteristics of the respondents compared to the academic factor characteristics. This may be because individual attributes, which are influenced by their gender and ethnicity, have been nurtured and cultivated in them for a long time. Therefore, it is quite difficult to change the way of life or culture that is practiced, and to some extent, it determines the personality as one grows up. However, from the educational perspective, the differences in the items are not significant. As such, education is capable of changing one's thinking and behaviour rather than personal characteristics, which are difficult to change because it depends on how a person is nurtured and brought up.

Therefore, as future leaders who will be involved in organisational policy, they must appreciate the differences that exist among the workforce. The differences among individuals must be carefully assessed since it has different effects on their behaviour. Creating effective human resources policies (i.e., recruitment and retention policies) will determine the quality of the workforce that companies want. The quality of the workforce ultimately would help companies to achieve their goals, and indirectly, contribute to the country's economic prosperity.

\section{Conclusion}

Incidences of fraud have increased over time, which have negatively affected economic growth, stock market stability and shareholder confidence in the quality of corporate governance. To prevent this from happening, it is important to understand the cause of these incidences, as understanding this will help to better understand why fraudulent or unethical activities occur. One of the possible causes is the temptation to be involved in unethical activities. Temptation can lead to a person's tendency or desire to engage in unethical activities, and a person's intention will influence his or her behaviour.

Therefore, it is important that a study be undertaken in this area so that appropriate measures or policies regarding fraud prevention can be formulated. As such, the purpose of this study is to examine how temptation could cause a person to be involved in an unethical event and what type of 
unethical behaviour he or she might show. As the country's business environment is also influenced by the quality of organisational leadership, this study focuses on students pursuing accounting programmes. They are the future business leaders who will directly be involved in the governance process of the company.

This study takes into account a number of student characteristics and makes a comparative analysis between them. Two major characteristics of students are investigated: demographic (ethnicity and gender) and academic-related factors (type of academic programme and the year of study). Students from UUM are selected since its accounting programmes are among the oldest in the country with a very large student enrolment.

Based on the 319-sample size, the descriptive analysis indicates that there is a possibility of students being involved in an unethical behaviour when they are tempted. With regards to the unethical behaviour intentions, the result suggests that intention to be involved in such behaviour is generally low.

The comparative analysis which is based on the demographic factor reveals that there are significant differences between males and females when they are tempted and both also show significant differences for the unethical behaviour intention factor. As for the ethnicity characteristics, significant differences can be observed when they are tempted, but not in the case of unethical behaviour intention. With regards to the academic-related factor, the analysis indicates that year of study and academic programme do not have many significant differences in the case of being involved in unethical activity when tempted and intention to commit unethical behaviour. Hence, the academic background is less likely to be able to explain the characteristics of people who will be involved in unethical activities, compared to the demographic factor.

The study provides insights for those involved in human capital development (e.g., education and human resources) into the aspects that need to be emphasised on in producing quality business leaders and developing human capital policy. It is important for them to understand the individual attributes and seriously look into a person's personal background, especially when making recruitment and retention decisions. This study also suggests that the academic background factor may be an effective prevention mechanism; thus, continuous education and training should be all companies' priority to ensure that unethical activities are controlled.

The result of the study, however, should be used with caution. Among the limitations of the study, is that it only focuses on one university and its accounting programmes, where the students are predominantly female. Further studies may focus on vocational and technological-related courses or areas where gender involvement is more balanced. Also, there are two major characteristics that are examined. These weaknesses open the opportunity for future studies to examine other possible factors contributing to unethical activities (e.g., the quality of a company's internal control), and include a range of unethical activities (such as breach of trust and corruption), which are becoming prevalent nowadays.

\section{Acknowledgement}

This study (SO Code: 14495) is funded by Yayasan Muhibah and the authors would like to gratefully acknowledge the generous support offered by Yayasan Muhibah, Tunku Puteri Intan School of Accountancy, the ASIAN Research Institute for Corporate Governance (ARICG) and Universiti Utara Malaysia. 


\section{References}

[1] Low, Mary, Howard Davey, and Keith Hooper. "Accounting scandals, ethical dilemmas and educational challenges." Critical perspectives on Accounting 19, no. 2 (2008): 222-254.

https://doi.org/10.1016/j.cpa.2006.05.010

[2] Tang, Thomas Li-Ping, and Toto Sutarso. "Falling or not falling into temptation? Multiple faces of temptation, monetary intelligence, and unethical intentions across gender." Journal of Business Ethics 116, no. 3 (2013): 529 552. https://doi.org/10.1007/s10551-012-1475-3

[3] Albrecht, W. Steve, Chad O. Albrecht, Conan C. Albrecht, and Mark F. Zimbelman. Fraud examination. Cengage Learning, 2011.

[4] Owusu, Godfred Matthew Yaw, Rita Amoah Bekoe, Theodora Aba Abekah Koomson, and Samuel Nana Yaw Simpson. "Temptation and the propensity to engage in unethical behaviour." International Journal of Ethics and Systems (2019). https://doi.org/10.1108/IJOES-04-2018-0057

[5] Lawson, R. A. "Is Classroom to Business Cheating Students' Related Propensity to Cheat in the" Real World." Journal of Business Ethics 49, no. 2 (2004): 189-199. https://doi.org/10.1023/B:BUSI.0000015784.34148.cb

[6] Sims, Randi L. "The relationship between academic dishonesty and unethical business practices." Journal of Education for Business 68, no. 4 (1993): 207-211. https://doi.org/10.1080/08832323.1993.10117614

[7] Mosbah, Aissa, and Kalsom Abd Wahab. "Chinese family business in Malaysia: development, culture and the family business philosophy." Social Sciences 8, no. 5 (2018): 1013-1021. https://doi.org/10.6007/IJARBSS/v8-i5/4436

[8] Rashid, Md Zabid Abdul, and Jo Ann Ho. "Perceptions of business ethics in a multicultural community: The case of Malaysia." Journal of Business Ethics 43, no. 1-2 (2003): 75-87.

https://doi.org/10.1023/A:1022963232042

[9] Gino, Francesca. "Understanding ordinary unethical behavior: Why people who value morality act immorally." Current opinion in behavioral sciences 3 (2015): 107-111. https://doi.org/10.1016/i.cobeha.2015.03.001

[10] Fishbein, Martin, and Icek Ajzen. "Belief, attitude, intention, and behavior: An introduction to theory and research." (1977).

[11] Ajzen, Icek. "The theory of planned behaviour: reactions and reflections." (2011): 1113-1127. https://doi.org/10.1080/08870446.2011.613995

[12] Ismail, Ahmed Rageh, and Bahtiar Mohamed. "The ethical intention of marketing students: the role of ethical ideologies, Machiavellianism and gender." International Journal of Ethics Education 2, no. 1 (2017): 67-75. https://doi.org/10.1007/s40889-016-0030-y

[13] Jamil, Rossilah, Jihad Mohammad, and Maalinee Ramu. "Antecedents of Unethical Behaviour Intention: Empirical Study in Public Universities in Malaysian Context." Journal of Academic Ethics 17, no. 1 (2019): 95-110. https://doi.org/10.1007/s10805-018-9312-7

[14] Ruiz-Palomino, Pablo, Alexis Bañón-Gomis, and Jorge Linuesa-Langreo. "Impacts of peers' unethical behavior on employees' ethical intention: Moderated mediation by Machiavellian orientation." Business Ethics: A European Review 28, no. 2 (2019): 185-205. https://doi.org/10.1111/beer.12210

[15] Nga, Joyce KH, and Evelyn WS Lum. "An investigation into unethical behavior intentions among undergraduate students: A Malaysian study." Journal of Academic Ethics 11, no. 1 (2013): 45-71. https://doi.org/10.1007/s10805-012-9176-1

[16] Chen, Jingqiu, Thomas Li-Ping Tang, and Ningyu Tang. "Temptation, monetary intelligence (love of money), and environmental context on unethical intentions and cheating." Journal of Business Ethics 123, no. 2 (2014): 197219. https://doi.org/10.1007/s10551-013-1783-2

[17] Hsiao, Chun-Hua, and Chyan Yang. "The impact of professional unethical beliefs on cheating intention." Ethics \& Behavior 21, no. 4 (2011): 301-316. https://doi.org/10.1080/10508422.2011.585597

[18] Gino, Francesca, Maurice E. Schweitzer, Nicole L. Mead, and Dan Ariely. "Unable to resist temptation: How selfcontrol depletion promotes unethical behavior." Organizational behavior and human decision processes 115, no. 2 (2011): 191-203. 
https://doi.org/10.1016/j.obhdp.2011.03.001

[19] Buckley, M. Ronald, Danielle S. Wiese, and Michael G. Harvey. "An investigation into the dimensions of unethical behavior." Journal of Education for Business 73, no. 5 (1998): 284-290.

https://doi.org/10.1080/08832329809601646

[20] Thiruvadi, Sheela. "Gender differences and audit committee diligence." Gender in Management: An International Journal (2012). https://doi.org/10.1108/17542411211269310

[21] Betz, Michael, Lenahan O'Connell, and Jon M. Shepard. "Gender differences in proclivity for unethical behavior." Journal of Business Ethics 8, no. 5 (1989): 321-324. https://doi.org/10.1007/BF00381722

[22] Haniffa, Rozaini Mohd, and Terence E. Cooke. "Culture, corporate governance and disclosure in Malaysian corporations." Abacus 38, no. 3 (2002): 317-349. https://doi.org/10.1111/1467-6281.00112

[23] Nelson, Sherliza Puat, and Susela Devi. "Audit committee experts and earnings quality." Corporate Governance: The international journal of business in society (2013).

[24] Lounsbury, John W., Eric Sundstrom, Jacob J. Levy, and Lucy W. Gibson. "Distinctive personality traits of information technology professionals." Computer and Information Science 7, no. 3 (2014): 38. https://doi.org/10.5539/cis.v7n3p38

[25] Gottschalk, Petter. "Gender and white-collar crime: only four percent female criminals." Journal of Money Laundering Control (2012). https://doi.org/10.1201/b16232 